\title{
Nutritional physiology
}

\begin{abstract}
Nutrition has evolved itself with respect to definition, principles, importance and dimension keeping in pace with the increasing trend of life-style modifiable diseases. There is a heavy demand for information regarding nutrition and setting right examples of balanced diet from the early phases of life such as childhood and adolescence. Along with implicating exercise and physical activity, education regarding nutrition is the need of the hour. Physiologists have an advantage in giving nutritional support to the general population.
\end{abstract}

Keywords: life-style modifiable diseases, nutrition, physiologists, junk food
Volume 2 Issue 2 - 2016

\section{Soumya Mishra \\ Department of Physiology, JIPMER, India}

Correspondence: Soumya Mishra, Department of Physiology, JIPMER, Dhanvantri Nagar, Puducherry-605006, India, Tel +919943326|49, Email drsoumya_mishra@yahoo.co.in

Received: February 13,2016 | Published: March 16, 2016

\section{Introduction}

With the expanding field of exercise physiology or sports medicine, apart from achieving physical fitness and enhanced levels of performance by athletes, physiologists have applied the benefits of exercise in prevention and management of various lifestyle modifiable disease conditions. However, we often overlook the backbone-link between "exercise" and "health". Proper diet and nutrition is the fundamental key to a healthy and positive life. Recent researches have defined nutrition science as "the study of food systems, foods and drinks, and their nutrients and other constituents; and of their interactions within and between all relevant biological, social and environmental systems". ${ }^{1}$ With growing awareness among the general public about nutrition and balanced diet, there has been a tremendous change in food pattern, a shift from "junk" food to healthy, less calorie, "zero trans-fat" foods. Even young children are getting motivated to avoid the fast-food chains and switching to foods that would keep them in "picture-perfect figures". But little do they understand that the "zero-trans-fat" foods are not actually fat-free and the authenticity of the advertisements on "nutritious foods" shown on television. Along with awareness of exercise and physical activity, there should be an increase in awareness regarding the aspects of proper nutrition. Childhood and adolescence are the prime areas concerns of nutrition science as they are at the developmental peak years and also formative years for good dietary habits along with exercise and positive outlook in life. ${ }^{2}$ Also they lay the basic foundation for future health risks such as hypertension, diabetes mellitus, cancer and other life-style-associated diseases. They are of the concept that "healthy" foods need time to be prepared and that might be the reason why they switch to easily available fast foods. Another common issue is that the healthier foods are priced higher than the less healthy or junk food. ${ }^{3}$ However, children should be encouraged to prepare a healthy snack by themselves which would give them motivation and change the notion that it is a time-taking procedure. In the process of preparing their own meal, they could be encouraged to calculate the number of calories contained in the snack and compare it with similar meal when purchased from fast food centers. Not just the younger generation, but also the adults and geriatric population need counseling regarding balanced diet and modifying their diet according to the prevailing disease conditions such as diabetes, hypertension, renal dysfunction, dyslipidemia, obesity, etc. ${ }^{4}$ The older population especially needs a lot of attention and care in terms of nutrients to protect them from malnutrition, constipation, and common syndromes of hypertension, diabetes, cancer, renal dysfunction, anemia, osteoporosis, etc.

\section{Conclusion}

Thus there is a great need to establish nutrition as a separate branch in physiology, to educate and provide adequate information regarding nutrients and diet at all the stages of life such as infancy, children, adolescents, adults, pregnancy, during lactation and old age. Physiologists are more aware of the body changes, requirements and demands at these different stages so they would be the best guides as nutritionists with a little more education and knowledge in-depth regarding the foods and nutrients available in each food. They can very well prescribe foods to prevent and cure various life-style diseases. This calls for further discussion on how to make them more competent and efficient for this purpose.

\section{Acknowledgements}

None.

\section{Conflict of interest}

Author declares that there is no conflict of interest.

\section{References}

1. Beauman C, Cannon G, Elmadfa I, et al. The principles, definition and dimensions of the new nutrition science. Public Health Nutr. 2005;8(6A):695-698.

2. Mishra S, Banerjee S, Sengupta TK, et al. Association of diet and anthropometric measures as cardiovascular modifiable risk factors in young adults. J Basic Clin Physiol Pharmacol. 2013:1-8.

3. Rao M, Afshin A, Singh G, et al. Do healthier foods and diet patterns cost more than less healthy options? A systematic review and metaanalysis. 2013;3(12):e004277.

4. Dash SC, Mishra J, Patro S, et al. Prevalance of diabetes, hypertension, renal dysfunction and hyperlipidemia among doctors of a medical college in Odisha. Intern J Physiol. 2013;1(2):130-134. 